\title{
Effect of prosthetic ankle units on roll-over shape characteristics during walking in persons with bilateral transtibial amputations
}

\author{
Steven A. Gard, PhD; ${ }^{1-3^{*}}$ Po-Fu Su, MS; ${ }^{1-2,4}$ Robert D. Lipschutz, CP; ${ }^{1,3,5}$ Andrew H. Hansen, PhD ${ }^{1,6}$ \\ ${ }^{1}$ Northwestern University Prosthetics-Orthotics Center, Department of Physical Medicine and Rehabilitation, \\ Feinberg School of Medicine, Northwestern University, Chicago, IL; ${ }^{2}$ Department of Biomedical Engineering, \\ McCormick School of Engineering, Northwestern University, Evanston, IL; ${ }^{3}$ Jesse Brown Department of Veterans \\ Affairs (VA) Medical Center, Chicago, IL; ${ }^{4}$ Hocksheng Trading Co, Ltd, Taipei, Taiwan; ${ }^{5}$ Center for Bionic Medicine, \\ Rehabilitation Institute of Chicago, Chicago, IL; ${ }^{6}$ Minneapolis VA Health Care System, Minneapolis, MN
}

\begin{abstract}
Some important walking functions are adversely affected or eliminated in prosthesis users because of reduced or absent ankle motion. This retrospective data analysis determined the effect of prosthetic ankle units on the characteristics of the ankle-foot roll-over shape in persons with bilateral transtibial amputations. Seventeen subjects were fitted with Endolite Multiflex Ankles to provide ankle plantar-/dorsiflexion during the stance phase of gait. Quantitative gait analyses were performed as subjects walked with (1) Seattle Lightfoot II feet (baseline condition) and (2) the prosthetic ankle units added. Roll-over shape radii and effective foot length ratio were calculated and compared for the two prosthetic configurations. When subjects walked with the ankle units, ankle motion increased $(p<0.001)$, peak ankle plantarflexion moment during stance decreased slightly, and ankle-foot roll-over shape radii were significantly decreased $(p<0.001)$ compared with the baseline condition. The effective foot length ratio of the roll-over shape was found to increase with walking speed ( $p<$ $0.001)$, but it was not significantly affected by the prosthetic ankle units $(p=0.07)$. Prosthetists and manufacturers are encouraged to consider the effect of combining prosthetic components on the overall characteristics of the prosthesis and the functions they impart to the user.
\end{abstract}

Key words: ankle, ankle motion, gait, kinematic, kinetic, prosthesis, prosthetic ankle units, rehabilitation, roll-over shape, transtibial amputation.

\section{INTRODUCTION}

The anatomical foot and ankle create a complex structure during walking, with the important functions of providing shock absorption and stability while contributing to the efficiency of walking. Three rockers of the foot and ankle [1] - the heel, ankle, and forefoot — act in a serial fashion during normal walking to advance the body forward over the stance leg. During the loading-response phase, the heel rocker sustains forward movement of the body without interruption and facilitates foot flat to ensure stability as the leg is progressively loaded, while simultaneously, restrained ankle plantarflexion provides shock absorption. Throughout midstance, the ankle rocker maintains forward progression of the body while the plantar surface of the foot

Abbreviations: $\mathrm{GRF}=$ ground reaction force, MAC $=$ Motion Analysis Corporation, MFCL $=$ Medicare Functional Classification Level, NICHD = National Institute of Child Health and Human Development, VA = Department of Veterans Affairs, VACMARL = VA Chicago Motion Analysis Research Laboratory.

*Address all correspondence to Steven A. Gard, PhD; NUPOC, 680 North Lake Shore Dr, Suite 1100, Chicago, IL 60611; 312-503-5700; fax: 312-503-5710.

Email: sgard@northwestern.edu

DOI:10.1682/JRRD.2010.07.0136 
remains in full contact with the ground. Finally, during terminal stance, the forefoot rocker enables the body to continue rolling over the foot as the ankle restrains dorsiflexion and the heel rises from the ground. These three discrete foot rocker mechanisms have an integrated effect during nondisabled walking to produce a functional rocker, or "roll-over shape" [2-3], which directly affects vertical motion of the body and is important for achieving smooth, efficient forward progression [4-5].

The ankle-foot roll-over shape can be calculated from quantitative gait data by transforming center of pressure data under the foot from a laboratory-based coordinate system into a shank-based coordinate system [2]. A circular arc is then fitted to the roll-over shape data, from which pertinent characteristics of the roll-over shape such as radius and arc length can easily be determined. The effective foot length is defined as the distance from the heel of the prosthetic foot to the most anterior portion of the roll-over shape [6]. The effective foot length ratio is the effective foot length divided by the total foot length. Scaled to an individual's height, the roll-over shapes that are created by nondisabled persons during walking have been found to be relatively invariant with walking speed [2-3], added weight [7], and changes in shoe heel height [8]. Presumably, nondisabled individuals maintain a particular roll-over shape to optimize walking biomechanics and efficiency. The concept of roll-over shape has also been applied to lower-limb prostheses for the evaluation and design of prosthetic feet $[3,6,9]$ and has been used as a basis for understanding principles of prosthetic alignment [10-11]. Recent work indicates that fitting prosthesis users with prosthetic feet that have inappropriate rollover shapes can reduce the quality of gait and comfort of the user [12-13].

Some of the important functions associated with the foot-ankle rocker mechanisms are adversely affected or eliminated during the gait of prosthesis users because of reduced or absent ankle motion. However, these functions may possibly be restored or improved by fitting users with prosthetic ankle joints. Prosthetic components that increase prosthetic compliance and produce greater sagittal plane ankle motion are often prescribed to provide shock absorption during the loading-response phase [1415]. Additionally, the compliance provided by prosthetic ankle units may allow the prosthetic foot to better accommodate uneven terrains, potentially improving stability during gait. For level walking, the prosthetic ankle units may also affect characteristics of the roll-over shape [10-
11]. During nondisabled gait, a fairly well-defined and relatively consistent relationship exists between ankle joint moment and ankle motion during stance that is dependent on the walking speed [16], suggesting stiffness values for artificial mechanical systems that might replace the anatomical system. Appropriate consideration should be given for the net effect of the combined stiffness when pairing a prosthetic ankle unit with a prosthetic foot. Therefore, a prosthetic ankle unit that increases ankle motion during stance phase may produce different ankle-foot roll-over shape characteristics than the prosthetic foot alone. Specifically, an ankle unit may reduce the foot's roll-over shape radius and effective length, yielding different gait biomechanics for the user.

Studies that investigate and compare different types of prosthetic foot-ankle interventions typically involve persons with unilateral transtibial amputations. However, analyzing and interpreting these data can be complicated by the contributions and compensations of the sound leg. Because people with bilateral amputations walk with two prostheses, they have fewer physiological control options available for them to compensate for prosthetic deficiencies. Therefore, we believe that this population of prosthesis users may offer distinct advantages when evaluating and comparing different types of prosthetic interventions, facilitating data interpretation while enabling deficiencies in the prostheses and their effect on gait biomechanics to be more readily identified and understood. Additionally, because people with bilateral lower-limb amputations expend considerably more energy during gait than individuals with unilateral amputations [17], they stand to benefit tremendously from improvements in prosthetic component design.

We previously conducted a study to determine how the gait characteristics of persons with bilateral transtibial amputations would be affected by the addition of prosthetic components that increase ankle motion [18]. After publication of that work, questions arose within our laboratory about how different types of prosthetic components may interact during walking to produce unanticipated effects. Specifically, we wondered whether the ankle-foot roll-over shape of a prosthetic foot would be modified by the addition of a prosthetic ankle unit that increases sagittal plane motion, which could significantly change gait biomechanics. For example, we know from biomechanical modeling of gait that the ankle-foot rollover shape directly affects the vertical displacement of the body, accelerations acting on the body center of mass 
from step to step, and ground reaction forces (GRFs) and could ultimately affect the work of walking and metabolic energy expenditure [4,19-20].

We conducted a retrospective analysis of data that were previously collected [18] to determine how prosthetic ankle-foot roll-over shape characteristics were affected by the addition of a prosthetic ankle component. By increasing motion at the ankle during stance phase with the addition of a compliant prosthetic ankle joint [18], we hypothesized that the roll-over shape radius of the prosthetic foot and ankle would be reduced. Similarly, we expected the increased ankle motion to decrease the effective foot length ratio of the ankle-foot system, since we assumed that the center of pressure under the prosthetic foot would not be able to progress as far anterior during stance phase when subjects walked with the ankle units.

\section{METHODS}

(Note: The following description of the methodology is limited to relevant information that directly pertains to the primary objective of this retrospective analysis of data, which were originally acquired as part of a more complex protocol that has been described in greater detail in a previously published article [18].)

\section{Subjects}

Individuals with bilateral transtibial amputations were recruited for this study "from clinics and prosthetics fitting centers in the Chicago metropolitan area. Criteria for inclusion were specified as individuals who were a minimum of [2 years postamputation]; used prostheses as their primary means of [ambulation]; and were without serious health issues that would directly affect gait. [Inclusion in the study was] not limited by age, weight, height, or residual limb length. All subjects who met these inclusion criteria were [informed of this study] by their physicians or prosthetists and invited to participate. Subjects signed consent forms that were approved by [Northwestern University's] Institutional Review Board” [18].

\section{Prosthetic Fitting}

The subjects' prostheses were modified in two stages: (1) the prosthetic feet were replaced with new, standardized feet; and (2) prosthetic ankle units were added to their prostheses. Initially, an experienced, certified prosthetist fitted all subjects bilaterally with Seattle Lightfoot II feet (Trulife USA; Poulsbo, Washington) having the manufacturer's recommended keel stiffness based upon their weight and activity level. "Subjects [used] their existing [sockets] and suspension type. The bench alignment of the [subjects'] prostheses was based [upon] the manufacturer's recommendations for the Seattle Lightfoot II. The prostheses were then fitted on the subjects and dynamic alignment was performed at the discretion of the prosthetist as subjects walked in the laboratory" [18]. After a 2-week accommodation period, the subjects returned to the laboratory and participated in the baseline quantitative gait analysis.

Following the baseline gait analysis session, subjects were fitted bilaterally with Endolite Multiflex Ankles (Endolite North America; Centerville, Ohio). When the research prosthetist added the ankle units, no realignment of the prostheses was performed. These components primarily provide plantar-/dorsiflexion movement, but also allow a small amount of inversion/eversion and transverse plane rotation. The stiffness of the Endolite Multiflex Ankle is controlled by combining different durometer viscoelastic elements. Specifically, the stiffness of the "ball" element controls plantarflexion range and the stiffness of the "snubber" element controls dorsiflexion range. An appropriate ball and snubber combination was selected for each subject based upon the manufacturer's recommendation given the subject's weight and activity level. "[The] prosthetist confirmed that [the ankle] components were adjusted to best suit the needs of the subject, and ensured that the subject felt safe walking with the new prosthetic configuration” [18]. The subjects were permitted another 2-week accommodation period prior to the second gait analysis.

\section{Gait Data Acquisition}

Data collection and analyses for the study were conducted at the Department of Veterans Affairs (VA) Chicago Motion Analysis Research Laboratory (VACMARL). "[The VACMARL] has an eight-camera Eagle Digital Real-Time motion capture system (Motion Analysis Corporation [MAC]; Santa Rosa, California) that is used to measure marker movements. A modified Helen Hayes marker set [21] was used to define a biomechanical model of the participant. As the subject walked along the walkway, the positions of the markers were recorded by the motion analysis cameras mounted around the periphery of the room. Six force platforms (Advanced Mechanical Technology, Inc; Watertown, Massachusetts) located midway along the 
walkway and embedded flush with the floor were used to measure GRFs. Both the kinematic and kinetic data were collected using EVa Real Time Software (EVaRT, MAC; Santa Rosa, California)" [18]. "The kinematic data were acquired at $120 \mathrm{~Hz}$ and the kinetic data were simultaneously recorded at a sampling rate of $960 \mathrm{~Hz}$. The GRF and motion data [were used] to calculate joint moments via inverse dynamics using OrthoTrak software (MAC; Santa Rosa, California). During the gait analyses, the subjects were instructed to ambulate at their comfortable, freelyselected walking speed, then they walked at their fastest comfortable speed, and finally at their slowest comfortable speed" [22]. Walking trials at each speed were repeated until GRF data were collected with the force platforms for a minimum of three clean foot strikes for the left and right feet. During the experiment, subjects were permitted to use their customary assistive aids (i.e., canes) if they desired, and they were given the opportunity to rest at any time.

\section{Data Processing and Analysis}

Missing data points were interpolated in OrthoTrak using a cubic spline technique. The raw data were then filtered using a fourth-order, bidirectional, Butterworth, infinite-impulse response digital filter having an effective cutoff frequency of $6.0 \mathrm{~Hz}$. Because subjects used prostheses bilaterally and had a reasonably symmetric gait [22], only data collected from the left legs of the research subjects were analyzed for this investigation. Matlab (The MathWorks, Inc; Natick, Massachusetts) programs were used to calculate the mean walking speeds of subjects, peak-to-peak sagittal plane ankle rotation during stance phase, and peak ankle plantarflexion moment for each speed and for each prosthetic configuration. The ankle-foot roll-over shapes were computed using a custom-written Matlab program. The ankle-foot roll-over shape radius [2] and effective foot length ratio [23] were calculated for each subject for the two prosthetic conditions and the three walking speeds and then averaged across all subjects. The rollover shape radius was found using a nonlinear least-squares fitting routine of the roll-over shape data to the equation describing the lower arc of a circle [2]. The effective foot length ratio provides an estimate of the load-bearing capability of the prosthetic foot based upon the measurement of center of pressure progression during stance phase, normalized by foot length.

SPSS software (SPSS, Inc; Chicago, Illinois) was used to analyze the data with the level of statistical significance set at $p<0.05$. Statistical analysis of the data included a two $\times$ three repeated-measures analysis of variance to test the differences in the data for the two prosthetic configurations (baseline, Endolite Multiflex Ankles) and three walking speeds (slow, freely-selected, fast). The interaction term was also investigated when both factors were significant. When factors were found to be significant, pairwise comparisons were made using Bonferroni adjustments for multiple comparisons. Values for $p$ were adjusted by the software after the Bonferroni correction to maintain the significance level at $p<0.05$.

\section{RESULTS}

Nineteen subjects with bilateral transtibial amputations were enrolled in the study [18]. However, in postprocessing, we discovered that the data set for one subject was incomplete and another subject's roll-over shape radii data exceeded three standard deviations from the mean and was thus determined to be an outlier. Therefore, these two subjects were excluded from subsequent analyses. The age of the 17 subjects was $53.6 \pm$ 17.7 years (all data presented as mean \pm standard deviation where appropriate), and their height and mass were $172.9 \pm 7.5 \mathrm{~cm}$ and $77.3 \pm 15.1 \mathrm{~kg}$, respectively.

Data collections were performed at three different walking speeds. For the baseline condition, analysis of the group data indicated that subjects walked at a slow speed of $0.59 \pm 0.18 \mathrm{~m} / \mathrm{s}$, a freely-selected speed of $0.91 \pm$ $0.28 \mathrm{~m} / \mathrm{s}$, and a fast speed of $1.17 \pm 0.37 \mathrm{~m} / \mathrm{s}$ (Table). While walking with the ankle units, the subjects walked at a slow speed of $0.62 \pm 0.20 \mathrm{~m} / \mathrm{s}$, a freely-selected speed of $0.94 \pm 0.30 \mathrm{~m} / \mathrm{s}$, and a fast speed of $1.16 \pm 0.38 \mathrm{~m} / \mathrm{s}$ (Table). The slow, freely-selected, and fast walking speeds were determined to be statistically different from one another for each of the prosthetic conditions $(p<0.001)$. However, the slow, freely-selected, and fast walking speeds were not significantly different between prosthetic conditions $(p=0.42)$. Prosthetic ankle motion was significantly increased from a range of $13.0^{\circ} \pm 3.4^{\circ}$ during the stance phase of the baseline condition at the subjects' freely-selected speed to $19.4^{\circ} \pm 4.4^{\circ}$ when subjects walked with the prosthetic ankle units $(p<0.001$; Table, Figure 1(a)). The peak ankle plantarflexion moment during stance phase was observed to decrease slightly with the addition of the prosthetic ankle unit (Table, Figure 1(b)), but the change was statistically significant at only the slowest walking speed $(p=0.008)$. By plotting prosthetic 
Table.

Gait parameters for subjects $(n=17)$. Data presented as mean \pm standard deviation.

\begin{tabular}{|c|c|c|c|c|c|c|}
\hline $\begin{array}{l}\text { Walking } \\
\text { Speed } \\
\text { Category }\end{array}$ & $\begin{array}{l}\text { Prosthesis } \\
\text { Condition }\end{array}$ & $\begin{array}{c}\text { Walking Speed } \\
(\mathrm{m} / \mathrm{s})\end{array}$ & $\begin{array}{c}\text { Peak-to-Peak } \\
\text { Prosthetic “Ankle” } \\
\text { Motion }\left({ }^{\circ}\right)\end{array}$ & $\begin{array}{c}\text { Peak Ankle } \\
\text { Plantarflexion } \\
\text { Moment }(\mathbf{N} \cdot \mathbf{m} / \mathbf{k g})\end{array}$ & $\begin{array}{c}\text { Ankle-Foot Roll- } \\
\text { Over Shape } \\
\text { Radius/Height }\end{array}$ & $\begin{array}{c}\text { Effective Foot } \\
\text { Length Ratio }\end{array}$ \\
\hline \multirow[t]{2}{*}{ Slow } & Baseline & $0.59 \pm 0.18$ & $10.5 \pm 3.7$ & $1.03 \pm 0.12$ & $0.26 \pm 0.07$ & $0.65 \pm 0.06$ \\
\hline & $\begin{array}{l}\text { With Ankle } \\
\text { Units }\end{array}$ & $0.62 \pm 0.20$ & $16.1 \pm 4.1^{*}$ & $0.96 \pm 0.13^{*}$ & $0.18 \pm 0.03^{*}$ & $0.63 \pm 0.08$ \\
\hline $\begin{array}{l}\text { Freely- } \\
\text { selected }\end{array}$ & Baseline & $0.91 \pm 0.28$ & $13.0 \pm 3.4$ & $1.12 \pm 0.12$ & $0.24 \pm 0.05$ & $0.69 \pm 0.05$ \\
\hline \multirow[t]{2}{*}{ Fast } & Baseline & $1.17 \pm 0.37$ & $14.5 \pm 3.6$ & $1.18 \pm 0.17$ & $0.25 \pm 0.05$ & $0.71 \pm 0.05$ \\
\hline & $\begin{array}{l}\text { With Ankle } \\
\text { Units }\end{array}$ & $1.16 \pm 0.38$ & $21.2 \pm 4.7^{*}$ & $1.14 \pm 0.20$ & $0.18 \pm 0.04^{*}$ & $0.70 \pm 0.05$ \\
\hline
\end{tabular}

ankle moment against ankle rotation during stance phase, we can determine the ankle "stiffness" [24] and the reduction that occurs with the addition of the prosthetic ankle unit becomes evident (Figure 2). This reduction in stiffness was observed in all of the research subjects when they walked with the prosthetic ankle units.

Research subjects demonstrated consistent differences between the calculated ankle-foot roll-over shapes when they walked with and without the prosthetic ankle units (Figure 3). When subjects walked with the Endolite Multiflex Ankles, their roll-over shape radii were determined to be significantly decreased compared with the baseline condition (Seattle Lightfoot II feet alone) ( $p<$ 0.001; Table). The prosthetic ankle-foot roll-over shape radii for the baseline condition were larger than the median of those previously reported for 24 nondisabled individuals [3], but when the subjects with amputations walked with the ankle units, the roll-over shape radii more closely approximated those of the nondisabled controls (Figure 4). Speed was not a significant factor in accounting for this difference in roll-over shape radius between the two prosthetic configurations ( $p=0.39$ ), nor was the interaction between the prosthetic configuration and speed found to be significant $(p=0.16)$. The effective foot length ratio of the roll-over shape was found to increase with walking speed ( $p<0.001$; Figure 5), but it was not significantly affected by the prosthetic ankle units ( $p=0.07$; Table). Effective foot length ratio was not affected by the interaction term between the prosthetic configuration and walking speed $(p=0.12)$.

\section{DISCUSSION}

The Seattle LiteFoot II provides simulated prosthetic ankle motion by compressing the heel and bending the keel during the stance phase of walking, which is manifested as ankle rotation because of the marker placement and data processing that is used for the quantitative gait analysis. In this study, the subjects walked at freelyselected speeds with approximately $13^{\circ}$ of peak-to-peak ankle plantar-/dorsiflexion without the prosthetic ankle components (Table, Figure 1(a)).

Endolite's Multiflex Ankle incorporates a physical articulation immediately proximal to its connection with the foot that decreases rotational stiffness of lower-limb prostheses and thus increases ankle motion during loadbearing. When subjects walked with the Endolite Multiflex Ankles, their mean sagittal plane ankle range of motion was significantly higher than with the baseline configuration (Table, Figure 1(a)), increasing on average by $6^{\circ}$ to $7^{\circ}$. In fact, the motion provided by the prosthetic ankle joint and foot combination was comparable to that of the nondisabled individuals walking at similar speeds, differing by only about $1^{\circ}$ to $2^{\circ}$ during stance phase [18]. The prosthetic ankle unit specifically increased peak prosthetic ankle dorsiflexion during mid- to late stance phase, apparently restoring some portion of the anatomical ankle and forefoot rocker mechanisms.

The addition of the Endolite Multiflex Ankle was found to have a significant effect on the prosthetic ankle-foot rollover shapes for the subjects' prostheses (Table, Figure 3). The increased ankle rotation during stance phase decreased 
(a)

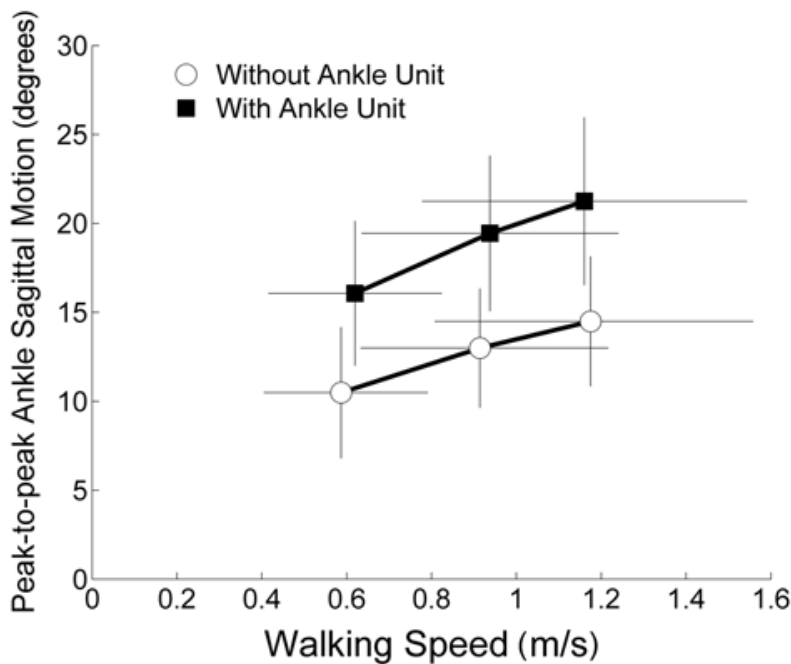

(b)

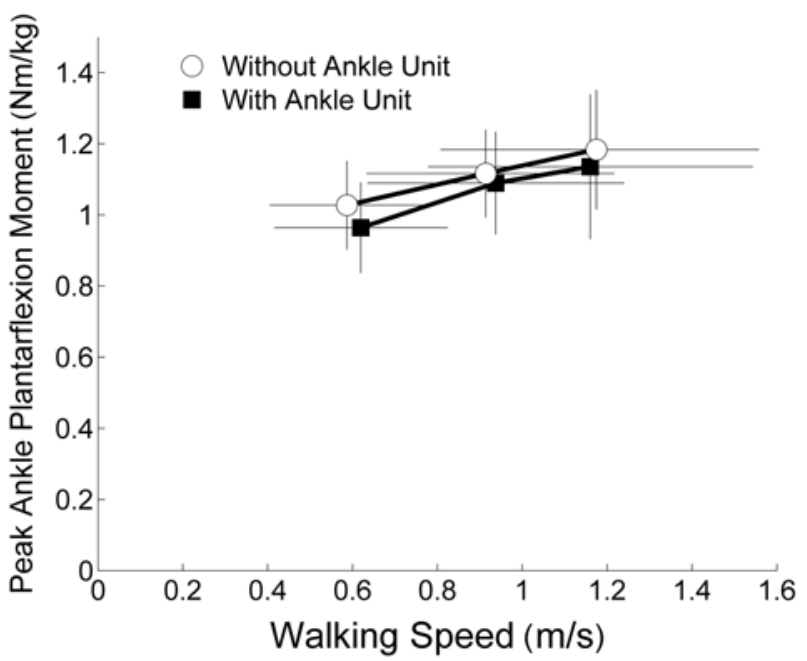

Figure 1.

(a) Measured prosthetic ankle motion was significantly increased with addition of Endolite Multiflex Ankles $(p<0.001)$. (b) Peak ankle plantarflexion moment during stance phase was reduced when subjects walked with ankle units. Reduction in peak ankle plantarflexion moment was significant at only slowest speed $(p=0.008)$.

the radius of the ankle-foot roll-over shape, supporting our hypothesis (Figure 4). We had originally anticipated that the ankle-foot roll-over shape radius for the baseline condition would be closer to that of the nondisabled controls and that adding the ankle units would produce a roll-over shape radius that would be too small. However, somewhat unexpectedly, the decreased radius of the ankle-foot roll-over shape when the subjects walked with the ankle units better approximated that of nondisabled individuals than the baseline condition. Nonetheless, if a prosthesis user is

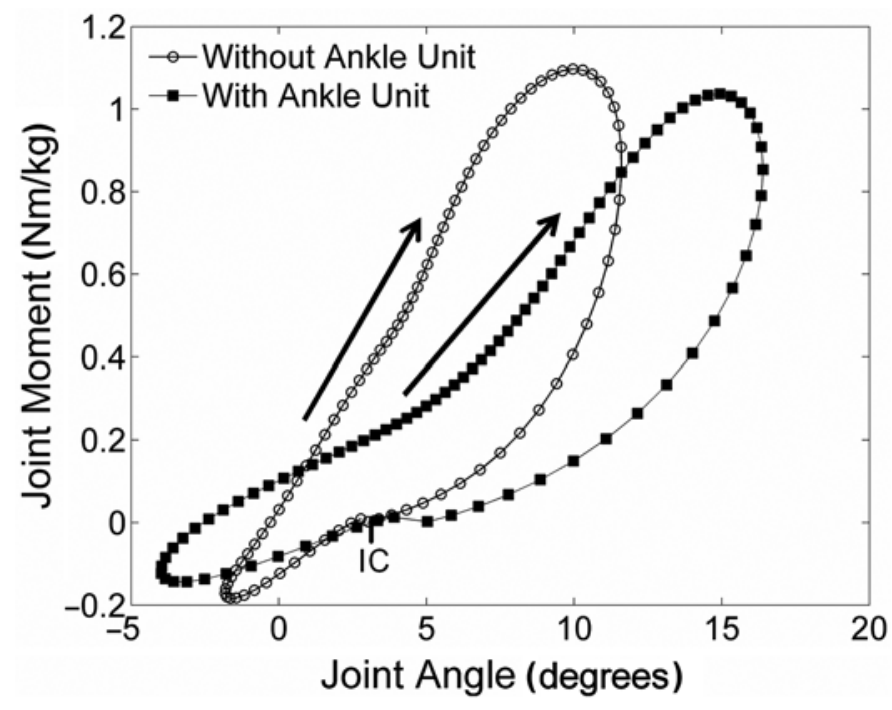

Figure 2.

Ankle moment plotted against ankle rotation during stance phase from one subject walking with and without ankle units at their freelyselected speed. Initial contact (IC) of foot with ground for each condition occurred at approximately same ankle moment-angle position in each curve. Arrows indicate time progression during stance. Ankle "stiffness"* can be determined at each point in time from slope of lines tangent to this curve. These curves illustrate that ankle stiffness was reduced with prosthetic ankle unit.

*Latash ML, Zatsiorsky VM. Joint stiffness: Myth or reality? Hum Mov Sci. 1993;12(6):653-92. DOI:10.1016/0167-9457(93)90010-M.

wearing a prosthetic foot that provides a roll-over shape that is deemed appropriate for their height, then adding an ankle unit to their prosthesis will reduce the roll-over shape radius. Walking on a roll-over shape with a radius that is too small could produce a slower walking speed [25], a shorter contralateral limb step length [23], excessive vertical motion of the body during prosthetic stance phase [4], larger contralateral impact forces [26-27], and a general increase in the work of walking, while reducing the energy efficiency [26]. Contrary to our expectations for the second hypothesis, the effective foot length ratio of the ankle-foot system was not significantly affected by the addition of the prosthetic ankle unit (Table, Figure 5). We anticipated that a more compliant ankle would reduce the ability to propagate the center of pressure anteriorly under the foot and would thus lead to a reduced ankle lever arm, decreasing the ankle plantarflexion moment in late stance. This expectation may be best illustrated by considering the hypothetical situation of someone walking with a transtibial prosthesis having an ankle mechanism that freely rotates and provides no resistance (i.e., zero stiffness) during 


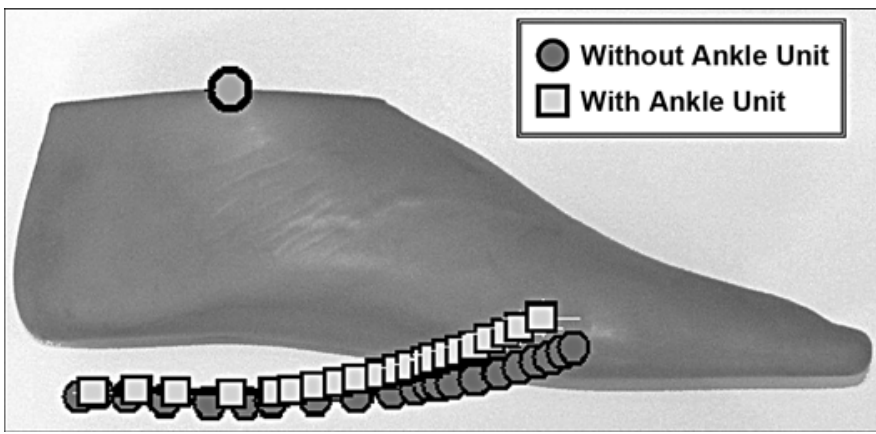

Figure 3.

Average ankle-foot roll-over shape for group of subjects walking with and without Endolite Multiflex Ankles at their freely-selected speed. (Photograph of prosthetic foot in background is for reference purposes only and is not necessarily scaled to data. Feet were tested in shoes.)

stance phase. In this extreme example, the center of pressure under the prosthetic foot would remain directly beneath the ankle joint axis of rotation throughout stance phase, effectively providing the user with a point contact on the ground. For this special case of zero ankle joint stiffness, the center of pressure would not propagate anteriorly under the foot, the ankle joint moment would be zero during the entire stance phase, and the roll-over shape radius and the effective foot length ratio would both be zero. In reality, however, we did not set prosthetic ankle stiffness to zero in this study but merely reduced it from what it was in the baseline condition. Therefore, only slight reductions in the ankle plantarflexion moment and effective foot length ratio were evident when subjects walked with the prosthetic ankle units (Table, Figure 1(b), Figure 5), but these differences were not statistically significant overall.

Several limitations to this study warrant discussion. First, the population that we investigated is novel in that subjects had bilateral transtibial amputations. However, the majority of lower-limb prosthesis users have unilateral transtibial amputations. Additionally, many unilateral transfemoral prosthesis users are fitted with and may benefit from prosthetic ankle units to increase sagittal plane motion. Presumably, the external validity of our study is such that these findings can readily be extrapolated to all users of lower-limb prostheses - unilateral and bilateral, transtibial, and transfemoral-though the effect of sagittal plane prosthetic ankle motion may be more or less dramatic on prosthetic ankle-foot roll-over shape characteristics. Biomechanically, we are unable to identify any apparent reasons why other lower-limb prosthesis users who are fitted with a compliant ankle mechanism would experience

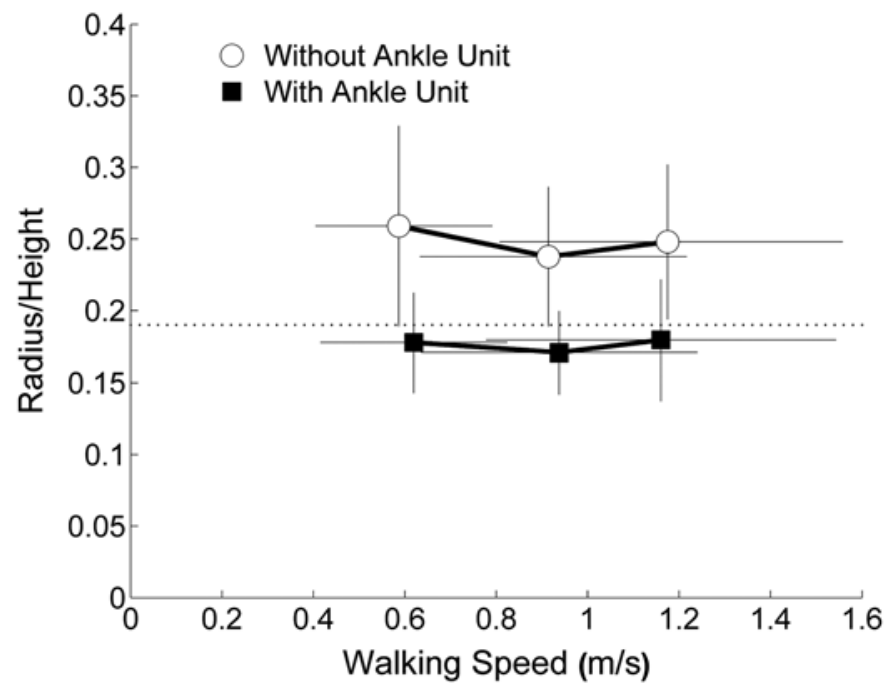

Figure 4.

Roll-over shape radius (normalized by body height) was decreased significantly ( $p<0.001)$ when subjects walked with Endolite Multiflex Ankles (With Ankle Unit) compared with baseline (Without Ankle Unit). Dotted line represents median ankle-foot roll-over shape radius scaled to height for group of nondisabled adults.

*Hansen AH. Roll-over characteristics of human walking with applications for artificial limbs [dissertation]. Evanston (IL): Northwestern University; 2002.

effects that are different from those that we have reported in this study. However, additional studies are necessary to validate our findings and to make conclusive determinations of these effects in different amputee populations.

A second limitation is that the prosthetic components that were fitted on some of the research subjects in this study may not have been considered appropriate. The Endolite Multiflex Ankle is indicated for a Medicare Functional Classification Level (MFCL) K2 and higher, while the Seattle Lightfoot II is indicated for a minimum K3 level. From a billing perspective, the Center for Medicare and Medicaid Services does not focus on the MFCL of individuals with bilateral lower-limb amputations when considering reimbursement. Nonetheless, in clinical practice it is important for the prosthetist to perform appropriate assessments to determine whether a client with bilateral transtibial amputations demonstrates the functional abilities required to walk with these types of components. The research subjects in this study were not categorized using the MFCL system; presumably the majority of them would be functionally classified as K3 (i.e., community ambulator with variable cadence), but some would be considered as 


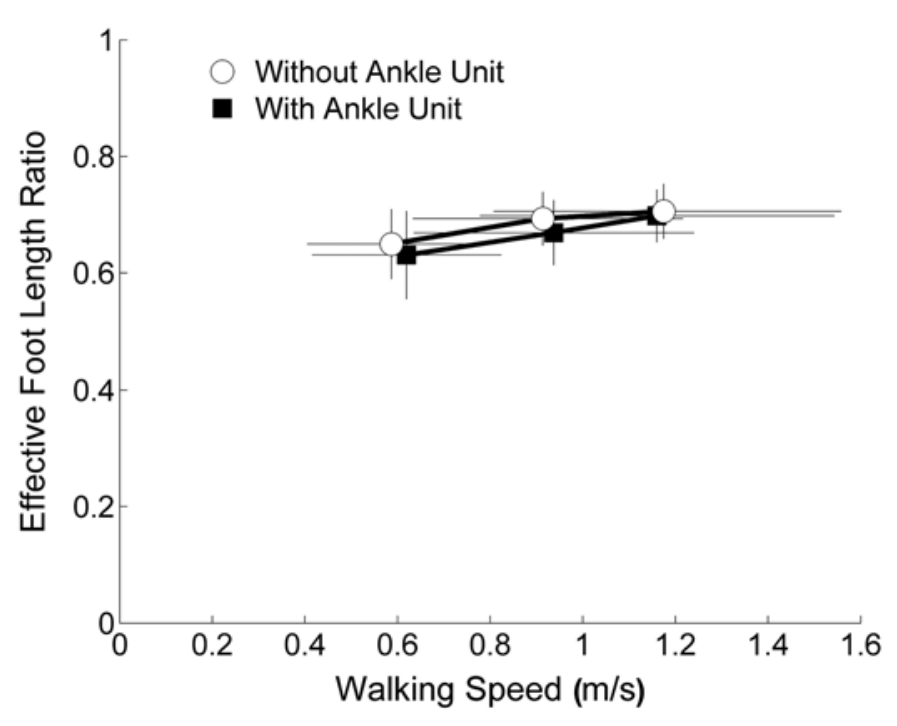

Figure 5.

Effective foot length ratio did not change significantly when subjects walked with Endolite Multiflex Ankles (With Ankle Unit) compared with baseline (Without Ankle Unit).

K2 (i.e., limited community ambulator). When we enrolled individuals for this study, their functional abilities with the experimental components were of primary concern. With each prosthetic configuration, subjects were independently evaluated by the research prosthetist to ensure that they could ambulate safely and comfortably without assuming unnecessary risk for the sake of the research study objectives. Based upon these individual functional assessments, no subjects were determined to be ineligible for participation in the study.

Another potential limitation of our investigation involves the use of assistive devices by research subjects. Four of the subjects used a single-point cane to assist walking during the gait analyses. It is currently not known how use of a cane by prosthesis users during walking affects prosthetic ankle-foot roll-over shape characteristics. Presumably, if the user does not apply significant force through the cane during walking and reduce the load borne through the prosthesis, then the cane probably has little or no effect on GRF magnitudes or center of pressure progression under the prosthetic foot. For this study, these four subjects always held the cane in their right hand and in contact with the ground during the left stance phase. Data showed that these subjects demonstrated good symmetry during gait and had similar vertical GRFs for both legs, indicating that they did not rely appreciably on the assistive device to provide load-bearing. Instead, they probably used the cane to provide a sense of security, improve perceived stability, and prevent falling if perturbed while walking. For this reason, we concluded that the quantitative gait data acquired from these four subjects were not appreciably affected and did not exclude them from subsequent analyses.

Finally, a couple of limitations should be noted with regard to the procedures that were followed in the study protocol. Research subjects were provided with a 2-week accommodation period after being fitted with the prosthetic feet and again after they were fitted with the prosthetic ankle units. We do not know for certain that this 2-week period was sufficient for the subjects to fully accommodate to the new prosthetic configurations. However, in the absence of clearly established guidelines or recommendations for what is considered an appropriate accommodation period following a change in prosthetic componentry, we specified the 2-week period. We have previously used a 2-week accommodation period in other studies that have compared different prosthetic foot/ankle mechanisms in people with unilateral transtibial amputation, and that period seemed sufficient. The question regarding accommodation periods for studies that test subjects wearing different prosthetic configurations will likely remain unanswered until systematic research investigations are conducted to identify reliable and consistent metrics for monitoring and tracking the accommodation of prosthesis users to particular changes in componentry. It is likely that accommodation times will differ depending upon the component that is changed.

Another potential issue with the prosthetic fitting protocol concerns the prosthetic alignment, particularly when the subjects were fitted with the ankle units. As indicated in the "Methods" section, for the baseline condition, the research prosthetist bench-aligned the Seattle Lightfoot II feet per the manufacturer's recommendations and then performed routine dynamic alignment while the subjects wore their modified prostheses. When the research prosthetist fitted subjects with the Endolite Multiflex Ankles, no realignment of the prostheses was performed. However, some subjects indicated that the increased motion provided by the ankle units caused them to feel unstable during standing and walking. From a clinical perspective, some of this perceived instability could have been addressed by realigning the prostheses. Instead, the research prosthetist chose to alter the ball/snubber stiffness of the Endolite Multiflex Ankles, thereby maintaining the same prosthetic alignment for both test conditions, while ensuring that the 
subjects felt safe and stable while walking with the ankle units. In fact, the manufacturer suggests that the ankle stiffness settings for people with bilateral amputations may need to be different from those recommended for people with unilateral amputation. Credible arguments could probably be made about whether or not the prostheses in this study should have been realigned after the ankle units were added. We chose to maintain the prosthetic alignment that was determined at baseline, prior to the addition of the ankle units. From our perspective, modification of the prosthetic alignment could have affected ankle-foot rollover shapes in addition to those changes produced by the addition of the ankle units, making data interpretation difficult.

The clinical implication of our results is that prosthetists should carefully consider the effect of combining different prosthetic components on overall functional performance of their patient. Prosthetic ankle units may be fitted on individuals to improve stability during level walking by allowing the prosthetic foot to plantarflex during early stance phase and enable the plantar surface of the foot to contact the ground sooner, which has been hypothesized to improve stability [25]. Additionally, prosthetic ankle units may enhance stability on uneven terrains by enabling the foot to accommodate to different surfaces. However, as results from this study indicate, the addition of a prosthetic ankle unit will likely alter the roll-over shape from that provided by the prosthetic foot alone. Surprisingly, the addition of prosthetic ankle units was determined to be beneficial on roll-over shape characteristics because they reduced the radius to a value comparable to that of nondisabled individuals without decreasing the effective foot length. This finding further underscores the need for prosthetists to have a good understanding of the functions being provided to the user by the prosthesis and to consider how the combination of prosthetic components affects gait biomechanics. There may be cases in which a prosthetic foot provides appropriate roll-over shape characteristics to the user but adding a compliant ankle mechanism could substantially reduce the roll-over shape radius and effective foot length, causing unanticipated effects on prosthetic foot dynamics and gait biomechanics. Therefore, for those types of situations, the prosthetist may consider selecting a prosthetic foot with a slightly stiffer or longer keel than they would normally fit on that individual to provide them with a more appropriate ankle-foot roll-over shape for the combination of the prosthetic foot and ankle unit.
Manufacturers of prosthetic components may want to consider making similar recommendations for prosthetic foot and ankle mechanism combinations. Doing so could potentially improve walking biomechanics and increase the efficiency of gait. Additional investigations are required to identify and weigh the different benefits and compromises that result by combining prosthetic feet having stiffer keels with more compliant ankle mechanisms, and vice versa, to determine how to best serve the needs of the prosthesis user and produce the greatest improvement in gait performance.

\section{CONCLUSIONS}

Prosthetic ankle units were found to reduce the radius of curvature of the prosthetic ankle-foot roll-over shape. However, the effective foot length ratios were unaffected by the addition of prosthetic ankle units. Prosthetists and manufacturers of prosthetic components are encouraged to carefully consider the effect of combining different prosthetic components on the overall characteristics of the prosthesis and the functions they impart to the user.

\section{ACKNOWLEDGMENTS}

\section{Author Contributions:}

Study concept and design: S. A. Gard.

Obtained funding: S. A. Gard.

Fitting of prosthetic components: R. D. Lipschutz.

Acquisition of data: P. Su.

Analysis and interpretation of data: P. Su, A. H. Hansen, S. A. Gard, R. D. Lipschutz.

Statistical analysis: P. Su, A. H. Hansen.

Drafting of manuscript: S. A. Gard, A. H. Hansen, P. Su,

R. D. Lipschutz.

Critical revision of manuscript for important intellectual content: S. A. Gard, A. H. Hansen, P. Su, R. D. Lipschutz.

Study supervision: S. A. Gard.

Financial Disclosures: The authors have declared that no competing interests exist.

Funding/Support: This material was based on work supported by the National Institute of Child Health and Human Development (NICHD), the National Institutes of Health (grant 1R01HD42592). Data for this project were acquired in the VACMARL of the Jesse Brown VA Medical Center, Chicago, Illinois.

Additional Contributions: We gratefully acknowledge Ms. Rebecca Stine, MS, for her assistance with data collection for this study, and Ms. Sara Koehler, MS, for providing statistical support. 
Institutional Review: This study was approved by Northwestern University's Institutional Review Board, and all subjects signed informed consent.

Participant Follow-Up: The authors do not plan to inform participants of the publication of this study. However, participants have been encouraged to check Capabilities (Northwestern University Prosthetics-Orthotics Center's quarterly newsletter) and our Web site for updated publications.

Disclaimer: This project's contents are solely the responsibility of the authors and do not necessarily represent the official views of the NICHD.

\section{REFERENCES}

1. Perry J. Gait analysis: Normal and pathological function. Thorofare (NJ): SLACK; 1992.

2. Hansen AH, Childress DS, Knox EH. Roll-over shapes of human locomotor systems: Effects of walking speed. Clin Biomech (Bristol, Avon). 2004;19(4):407-14. [PMID: 15109762] DOI:10.1016/j.clinbiomech.2003.12.001

3. Hansen AH. Roll-over characteristics of human walking with applications for artificial limbs [dissertation]. Evanston (IL): Northwestern University; 2002.

4. Gard SA, Childress DS. What determines the vertical displacement of the body during normal walking? J Prosthet Orthot. 2001;13(3):64-67. DOI:10.1097/00008526-200109000-00009

5. Gard SA, Fatone S. Biomechanics of lower limb function and gait. In: Condie E, Campbell J, Martina J, editors. Report of a consensus conference on the orthotic management of stroke patients; 2003 Sep 21-26; Ellecom, the Netherlands. Copenhagen (Denmark): ISPO Publications; 2004. p. 55-61.

6. Hansen AH, Sam M, Childress DS. The effective foot length ratio: A potential tool for characterization and evaluation of prosthetic feet. J Prosthet Orthot. 2004;16(2):41-45. DOI:10.1097/00008526-200404000-00002

7. Hansen AH, Childress DS. Effects of adding weight to the torso on roll-over characteristics of walking. J Rehabil Res Dev. 2005;42(3):381-90. [PMID: 16187250]

DOI:10.1682/JRRD.2004.04.0048

8. Hansen AH, Childress DS. Effects of shoe heel height on biologic rollover characteristics during walking. J Rehabil Res Dev. 2004;41(4):547-54. [PMID: 15558383]

DOI:10.1682/JRRD.2003.06.0098

9. Sam M, Childress DS, Hansen AH, Meier MR, Lambla S, Grahn EC, Rollock JS. The 'shape\&roll' prosthetic foot: I. Design and development of appropriate technology for lowincome countries. Med Confl Surviv. 2004;20(4):294-306. [PMID: 15688881] DOI:10.1080/1362369042000285937
10. Hansen AH, Childress DS, Knox EH. Prosthetic foot rollover shapes with implications for alignment of trans-tibial prostheses. Prosthet Orthot Int. 2000;24(3):205-15.

[PMID: 11195355] DOI:10.1080/03093640008726549

11. Hansen AH, Meier MR, Sam M, Childress DS, Edwards ML. Alignment of trans-tibial prostheses based on roll-over shape principles. Prosthet Orthot Int. 2003;27(2):89-99. [PMID: 14571938] DOI:10.1080/03093640308726664

12. Klodd E, Hansen A, Fatone S, Edwards M. Effects of prosthetic foot forefoot flexibility on gait of unilateral transtibial prosthesis users. J Rehabil Res Dev. 2010;47(9):899-910. [PMID: 21174254] DOI:10.1682/JRRD.2009.10.0166

13. Klodd E, Hansen A, Fatone S, Edwards M. Effects of prosthetic foot forefoot flexibility on oxygen cost and subjective preference rankings of unilateral transtibial prosthesis users. J Rehabil Res Dev. 2010;47(6):543-52. [PMID: 20848367] DOI:10.1682/JRRD.2010.01.0003

14. Wirta RW, Mason R, Calvo K, Golbranson FL. Effect on gait using various prosthetic ankle-foot devices. J Rehabil Res Dev. 1991;28(2):13-24. [PMID: 2066867] DOI:10.1682/JRRD.1991.04.0013

15. Van Jaarsveld HW, Grootenboer HJ, De Vries J. Accelerations due to impact at heel strike using below-knee prosthesis. Prosthet Orthot Int. 1990;14(2):63-66.[PMID: 2235301]

16. Hansen AH, Childress DS, Miff SC, Gard SA, Mesplay KP. The human ankle during walking: Implications for design of biomimetic ankle prostheses. J Biomech. 2004;37(10): 1467-74. [PMID: 15336920] DOI:10.1016/j.jbiomech.2004.01.017

17. Waters RL, Mulroy S. The energy expenditure of normal and pathologic gait. Gait Posture. 1999;9(3):207-31. [PMID: 10575082] DOI:10.1016/S0966-6362(99)00009-0

18. Su PF, Gard SA, Lipschutz RD, Kuiken TA. The effects of increased prosthetic ankle motions on the gait of persons with bilateral transtibial amputations. Am J Phys Med Rehabil. 2010;89(1):34-47. [PMID: 20026945] DOI:10.1097/PHM.0b013e3181c55ad4

19. Morawski JM, Wojcieszak I. Miniwalker-A resonant model of human locomotion. In: Asmusser E, Jorgensen K, editors. Biomechanics VI-A, International Series on Biomechanics: Proceedings of the Sixth International Congress of Biomechanics; 1977 Jul; Copenhagen, Denmark. Baltimore (MD): University Park Press; 1978. p. 445-51.

20. McGeer T. Passive dynamic walking. Int J Robotics Res. 1990;9(2):62-82. DOI:10.1177/027836499000900206

21. Kadaba MP, Ramakrishnan HK, Wootten ME. Measurement of lower extremity kinematics during level walking. 
J Orthop Res. 1990;8(3):383-92. [PMID: 2324857]

DOI:10.1002/jor.1100080310

22. Su PF, Gard SA, Lipschutz RD, Kuiken TA. Gait characteristics of persons with bilateral transtibial amputations. J Rehabil Res Dev. 2007;44(4):491-501. [PMID: 18247246] DOI:10.1682/JRRD.2006.10.0135

23. Hansen AH, Meier MR, Sessoms PH, Childress DS. The effects of prosthetic foot roll-over shape arc length on the gait of trans-tibial prosthesis users. Prosthet Orthot Int. 2006;30(3):286-99. [PMID: 17162519] DOI:10.1080/03093640600816982

24. Latash ML, Zatsiorsky VM. Joint stiffness: Myth or reality? Hum Mov Sci. 1993;12(6):653-92. DOI:10.1016/0167-9457(93)90010-M

25. Perry J, Boyd LA, Rao SS, Mulroy SJ. Prosthetic weight acceptance mechanics in transtibial amputees wearing the Single Axis, Seattle Lite, and Flex Foot. IEEE Trans Rehabil Eng. 1997;5(4):283-89. [PMID: 9422453] DOI:10.1109/86.650279

26. Adamczyk PG, Collins SH, Kuo AD. The advantages of a rolling foot in human walking. J Exp Biol. 2006;209(20): 3953-63. [PMID: 17023589]

DOI:10.1242/jeb.02455
27. Powers CM, Torburn L, Perry J, Ayyappa E. Influence of prosthetic foot design on sound limb loading in adults with unilateral below-knee amputations. Arch Phys Med Rehabil. 1994;75(7):825-29. [PMID: 8024435]

Submitted for publication August 2, 2010. Accepted in revised form March 24, 2011.

This article and any supplementary material should be cited as follows:

Gard SA, Su P, Lipschutz RD, Hansen AH. Effect of prosthetic ankle units on roll-over shape characteristics during walking in persons with bilateral transtibial amputations. J Rehabil Res Dev. 2011;48(9):1037-48.

DOI:10.1682/JRRD.2010.07.0136

ResearcherID: Steven A. Gard, PhD: D-9935-2011

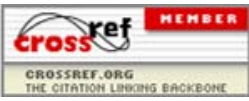


